\title{
Does Curriculum Practical Training Affect Engineers' Workplace Outcomes? Evidence from an Engineer Survey in China
}

\author{
Jing $\mathrm{Li}^{1}$, Yu Zhang ${ }^{2}$, Mun Tsang ${ }^{1} \&$ Manli $\mathrm{Li}^{2}$ \\ ${ }^{1}$ Columbia University, New York, USA \\ ${ }^{2}$ Tsinghua University, Beijing, China \\ Correspondence: Jing Li, Teachers College, Columbia University, New York, NY, 10027, USA. Tel: 212-678-3814. \\ E-mail: jing.li@tc.columbia.edu
}

Received: July 23, 2015

Accepted: August 12, 2015

Online Published: August 18, 2015

doi:10.5430/ijhe.v4n3p199

URL: http://dx.doi.org/10.5430/ijhe.v4n3p199

\begin{abstract}
With the increasing attention to STEM (Science, Technology, Engineering, and Math), hands-on Curriculum Practical Training (CPT) has been expanding rapidly worldwide as a requirement of the undergraduate engineering education. In China, a typical CPT for undergraduate engineering students requires several weeks of hands-on training in the industry.

So far the evidence on the effect of CPT is inconclusive for education researchers and policy makers. Employing a dataset collected from China in 2013, this study endeavors to identify the effect of CPT on engineering students' career development in China. This research uses two outcome variables to gauge work place outcomes: earnings and productivity.

With the Propensity Score Matching approach, this study shows several results: 1) most engineers benefit from their CPT and value this hands-on training experience; 2) without matching, CPT has a statistically significant positive contribution to future earnings. However, the significant effect vanishes after matching; 3) CPT was a significant positive determinant of productivity with and without matching; and 4) the effect of CPT was heterogeneous depending on personal characteristics.
\end{abstract}

Keywords: Engineering education, Practical training effects, Earnings, Productivity, Propensity score matching

\section{Introduction}

In the U.S., practical training programs allow international students to work outside of the school by engaging in hands-on training during their degree program or after it ends. Practical training provides valuable work experience by sharpening and adding to the skills learned in school. In the U.S., there are two types of practical training available for F-1 visa students: curricular practical training (CPT (Note 1)) and optional practical training (OPT). CPT must relate to a student's major and the experience must be part of the student's program of study while OPT doesn't have to be part of the program (U.S. Immigration and Customs Enforcement, 2015). Three characteristics of CPT are required for each student: CPT has to be part of curriculum, relate to the student's major, and takes place outside the campus.

Accordingly, CPT, though applied to international students only in the U.S., shares similar characteristics with Sheng Chan Shi Xi (practical training) in the context of China's engineering education (Note 2). In China, a typical CPT for undergraduate engineering students requires several weeks' hands-on training in the industry. This period provides students an opportunity to hone their skills on real-world problems rather than hypothetical ones, understand how to balance high efficiency with tight timelines, balance robust feature sets with low cost, and acquire working experience toward their career. For instance, Computer Engineering students need to learn skills in computer manufacturing, hardware design, assembly line process, equipment structure and operation (Note 3). CPT for students in other majors requires more time to complete. For instance, Civil Engineering students at Tongji University are required to take 40.5 weeks CPT (Chen, 1999). In terms of grading, usually it includes three parts: written exam (40\%), CPT report (40\%), performance and attendance $(20 \%)$. 


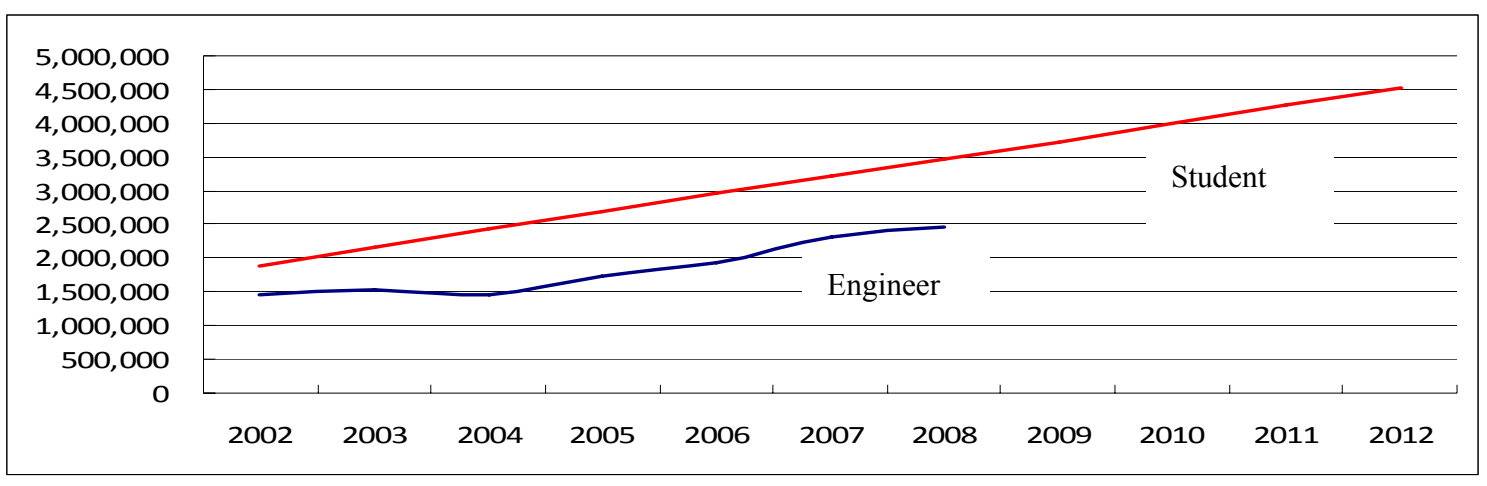

Figure 1. Enrollment of Engineering Students and Number of Engineers

(Source: China MOE and National Bureau of Statistics)

Aside from the cost of time, CPT means a high educational cost for universities. As we can see from Figure 1, China's engineering education has grown remarkably as the number of enrollment has doubled in the past 10 years, and this trend of growth continues. One third of China's undergraduate students are in an engineering program. In total, there were 4,522,917 undergraduate students enrolled in engineering programs in 2012 (Note 4). If the direct cost of CPT per student is RMB 20 (\$3.26) per day (Note 5), the national cost of a four week CPT will be about RMB 1.8 billion (\$290 million). And this estimate only serves as a lower-bound since other costs, such as costs of coordination and logistics, were not included.

Given the substantial built-in cost of CPT in engineering education, people may expect positive results. Yet, students, professors, and industry doubt the effectiveness of CPT (see Section 2). Hence, solid empirical analysis based on a high quality dataset is needed to ascertain the impact of CPT on students' post-college careers.

This study therefore tries to examine the effect of CPT on engineering students' career performance by answering the following research questions:

1) What's the effect of CPT on engineering students' post-college earnings?

2) What's the effect of CPT on engineering students' post-college productivity?

This paper is organized as follows: Section 1 provides an introduction of CPT and problems of CPT in China's engineering education. Section 2 reviews existing literature regarding CPT's effects and identifies research questions for this study. Section 3 is on research methodology; it discusses endogeneity problems in capturing the real casual effect, and explains the advantage of using quasi-experiment approach as the identification strategy. Descriptive statistics are presented in Section 4; and propensity score matching \& regression analysis in Section 5. The paper concludes with policy implications, limitations and future work in Section 6.

\section{Literature Review}

Despite the fact that CPT is built in an engineering program's curriculum and widely accepted by colleges and universities in China, researchers and practitioners have been debating about CPT's effectiveness for decades. As Table 1 indicates, the majority of previous studies hold a negative view of the current situation of CPT as part of an engineering education. In fact, only a handful of researchers are satisfied with CPT in their fields and programs. Since most existing researches were narratives, these studies discuss CPT's effectiveness in general with very few studies providing their methodology. Shao (2013) surveyed students about their CPT experience and used student's satisfaction as a proxy for effectiveness.

On the "Aye" side, Chen (1999) emphasized the significance of practical training for the Civil Engineering program in Tongji University. The 40.5 weeks of rigorous hands-on training counts for $25.1 \%$ of the total four-year program, assures that every graduate is equipped with qualified skills as a civil engineer. Echoed with Chen (1999), Qiao (2005) and Zhou (2008) confirmed the effectiveness of CPT in Material Engineering and Computer (and Electronic - based on the Table 1) Engineering respectively. Qiao (2005) reemphasized the importance of spending enough time at CPT so that students are able to produce quality products. Zhou (2008) found positive feedback from industries after Hunan University of Commerce added two more CPT weeks in the Computer Science curriculum. More recently, Zou (2009) reviewed the class of 2002 and 2003 Information Technology students and found that participating in CPT helps students gain an advantage in the job market. Similarly, Yan (2009) reported the success of extending the CPT to one or two whole semesters in Aviation programs. What is consistent from these positive view studies is that the length of 
CPT matters: the longer, the better. However, none of these five studies provide any individual level evidence to support their argument.

On the "Nay" side, Tong (2013), Liu (2005) and Tang, Xiao, \& Guo (2013) did not specify the field of study but looked at engineering programs as a whole. They agreed in general, that CPT cannot meet students need for acquiring skills and industry's demand for skilled workers. In contrast, Jia, Yan, \& Li (2006), Duan \& Chen (2013), Liu (2013) and Zhou \& Jiang (2013) focus on students in Mechanical Engineering. They agreed that the lag behind engineering education in practical training has hindered the development of China's manufacturing because many Mechanical Engineering graduates are not qualified for engineering positions. Lastly, they all shared the sentiment that a good CPT partner in industry is critical to college and universities, but finding a good one is not easy.

Overall, these studies found several key elements towards an effective CPT: sufficient funding; responsible professors and staff; and cooperative firms in the industry. As the debate of CPT heats up, a critical question has not yet been answered: how to motivate students? Only a few of these studies touched the point of how to motivate students (Xi \& Wu, 2002; Zou, 2009; Lin \& Pan, 2013). One way to motivate students is to show them the returns of CPT. However, very few studies have been done to explore the effect of CPT on an individual's labor market outcomes (such as successful employment, high earnings, etc.) and career development, even outside of China. In the U.S., Callahan \& Pedigo (2002) revealed that hiring managers demanded up-to-date skills and practical experience from their entry-level employee pool, and a practice-oriented curriculum strikes dead center on what students need to succeed in the job market. Unfortunately, Callahan \& Pedigo (2002) did not provide sufficient detailed micro-level evidence from their survey.

Table 1. Summary of Literature on CPT's Effects

\begin{tabular}{|c|c|c|c|c|}
\hline Research & Programs & Length of CPT & $\begin{array}{c}\text { Research } \\
\text { Method }\end{array}$ & Effect \\
\hline Chen (1999) & Civil Engineering & 40.5 weeks & Narrative & + \\
\hline Xi \& Wu (2002) & Aviation & Not indicated & Narrative & _ \\
\hline Liu (2005) & Engineering & Not indicated & Narrative & _ \\
\hline Qiao (2005) & Material & 12 weeks & Narrative & + \\
\hline Jia, Yan, \& Li (2006) & Mechanical & Not indicated & Narrative & _ \\
\hline Cao \& He (2008) & Material & 2-4 weeks & Narrative & _ \\
\hline Huang, Yang, \& Zhang (2008) & $\begin{array}{l}\text { Energy, Material Forming } \\
\text { and Control }\end{array}$ & 4 weeks & Narrative & - \\
\hline Wei, Ye, \& Zhang (2008) & Agriculture & 2-4 weeks & Narrative & _ \\
\hline Zhou (2008) & Computer, Electronic & 2-4 weeks & Narrative & + \\
\hline Yan (2009) & Aviation & $18-36$ weeks & Narrative & + \\
\hline Zou (2009) & Information & Not indicated & Narrative & + \\
\hline Wang, Zhang, \& Yang (2010) & Mining & 4 weeks & Narrative & _ \\
\hline $\mathrm{Wu}(2011)$ & Geodesy, Geometrics & Not indicated & Narrative & _ \\
\hline Guo (2012) & Pharmacy & Not indicated & Narrative & _ \\
\hline Duan \& Chen (2013) & Mechanical & 4 weeks & Narrative & _ \\
\hline Lin \& Pan (2013) & Hydrology & 4 weeks & Narrative & _ \\
\hline Liu (2013) & Mechanical & 4 weeks & Narrative & _ \\
\hline Shao (2013) & $\begin{array}{c}\text { Chemical, Textile, } \\
\text { Architecture, Mechanical }\end{array}$ & $1-2$ weeks & Survey & - \\
\hline Tang, Xiao, \& Guo (2013) & Engineering & Not indicated & Narrative & _- \\
\hline Tong (2013) & Engineering & Not indicated & Narrative & - \\
\hline Zhao (2013) & Electronics & 1-2 weeks & Narrative & _ \\
\hline Zhou \& Jiang (2013) & Mechanical & 2-4 weeks & Narrative & _ \\
\hline
\end{tabular}


In sum, there are mixed findings on CPT outcomes and there is no research about the impact of CPT on engineers' workplace outcomes in China. The methodological issues including endogeneity of CPT participation should be carefully addressed so as to make the results more convincing. The lack of research on the effect of CPT is mainly due to the difficulty of collecting data and lack of comprehensive data. In terms of methodology, previous studies merely use narrative (not even descriptive analysis) and conduct very few data analysis. More and better empirical studies on $\mathrm{CPT}$ are sorely needed.

Hence, this study aims to go beyond existing studies on the same topic in several ways: a) it uses national survey data (instead of one school case); b) it uses propensity score matching method (instead of narrative or qualitative approach); and c) it measures the impact of CPT in the long-term (instead of short-run).

\section{Identification Strategy}

Quantitative identification of the causal effect of CPT is difficult because of data constraint and technical problems such as endogeneity (i.e., participation in CPT is determined by some exogenous variable which also determine the dependent variable). Hence, most existing studies used narrative approaches (as Table 1 indicates).

Before the discussion of identification strategy to estimate the return to CPT, a brief explanation of the theoretical model (returns to education) is needed because the empirical model and the data collection are based on the theoretical model. Private return to education is usually measured by the net benefits one can expect from additional schooling (Carnoy, 1995). Two ways are widely used to estimate the Rates of Return (RoR) to education: Net Present Value (NPV) (Grubbström, 1967) and Mincer's method (Mincer, 1958) (Note 6).

$$
N P V=\sum_{1}^{n} \frac{B_{i}-C_{i}}{(1+r)^{i}},(i=1, \ldots, n)
$$

Where B is benefit, $\mathrm{C}$ is cost, $\mathrm{n}$ is the periods of time. By setting NPV equal to zero, we can calculate the internal rate of return (IRR), which is the Rate of Return (RoR) to education.

Mincer's method estimates Rates of Return by an Ordinary Least Square (OLS) regression with earnings as the dependent variable and years of schooling as the independent variable.

$$
Y=\alpha+\beta E d u+\not X+\varepsilon
$$

Where $\mathrm{Y}$ is the log of earnings; Edu is the years of schooling; $\mathrm{X}$ is a vector of covariates. $\beta$ is the RoR to education. It should be noted that $\mathcal{E}$ is an error term, which is assumed to be normally distributed and is NOT correlated with Edu or X.

In this research, we attempt to replace Edu in the model with CPT and estimate it as the RoR to CPT because Edu is the same for all college students.

$$
Y=\alpha+\beta_{C P T} C P T+\gamma X+\varepsilon
$$

However, we still need to deal with the endogeneity problem within the classic returns to education model. Recall that Mincer's method assumes that $\mathcal{E}$ is normally distributed and is NOT correlated with Edu or X, so if it is correlated with CPT or X, OLS estimates are likely to be biased as assumptions never hold. Omitted variable is one of the reasons for the bias. For instance, higher earnings of the more educated may be due to unmeasured effects of social and family connections, higher ability, and greater effort and persistence. Most of the studies (Griliches and Mason, 1972; Bound and Solon, 1999) pointed out that education is endogenous. Some confounding covariates are not easy to observe and hard to measure precisely, such as ability and motivation. The omission of these variables may cause upwards bias if their correlation with $\mathrm{Y}$ and Edu are the in the same direction. For example, higher ability people tend to earn more and also more likely to stay in school longer, because school is easy for them (Taubman, 1976). Unfortunately, this bias may stay true in the CPT model.

$$
Y=\alpha+\beta_{C P T}^{\prime} C P T+\not X+\eta A+\varepsilon
$$


Where A refers to ability, $\eta$ is the coefficient of ability, and $\beta_{C P T}^{\prime}$ is the unbiased estimate of RoR. Referred to in [3], we can get $\beta_{C P T}=\beta_{C P T}{ }^{\prime}+\eta b_{A C P T}$, where $b_{A C P T}$ is the regression coefficient of ability on CPT. Since $b_{A C P T}>0$, the OLS estimate is upwards biased.

Thus, in treatment (Note 7) circumstances, the difference in outcome between the treated and control may depend on characteristics that affects whether a person will receive the treatment or not, rather than the true effect of the treatment per se. In order to tease out the true treatment effect, this study endeavors to address the endogeneity problem with Propensity Score Matching (PSM). The PSM method says that rather than controlling for all the variables in X, it is sufficient to control for just the propensity score, which is just a one-number summary of X (Gelman and Hill, 2006).

$$
e(X)=\operatorname{Pr}(Z=1 \mid X)
$$

Where $\mathrm{Z}$ is the treatment variable (participating CPT students in this research) and $\mathrm{X}$ is a vector of pre-treatment covariates.

If the estimand we want to estimate is the average treatment effect on the treated (ATT),

$$
E[Y(1)-Y(0) \mid Z=1]=E[Y(1) \mid Z=1]-E[Y(0) \mid Z=1]
$$

And if the assumption of ignorability (Note 8 ) holds and we match on the propensity score

$$
E[Y(0) \mid Z=1, e(X)]=E[Y(0) \mid Z=0, e(X)]
$$

Therefore we should be able to get unbiased treatment effect estimate

$$
\begin{aligned}
& E\left[Y(1) \mid Z=1, e(X) \text { with } \bar{Y}_{Z=1, e(X)}\right. \text { and } \\
& E\left[Y(0) \mid Z=1, e(X) \text { with } \bar{Y}_{Z=0, e(X)}\right.
\end{aligned}
$$

In practice, this means to use the matched groups to estimate each mean.

The procedure for using PSM can be summarized as three steps: 1) search for a close-balanced propensity score model on an individual's pre-treatment characteristics; 2) estimate the individual's propensity score with probit/logit; and 3) run a regression on treatment and covariates with the outcome as the dependent variable (Guo and Fraser, 2010). The reason for emphasizing balancing in step one is because we want to make sure that for each treatment group member, there is a control group member that is sufficiently similar that we believe they can act as an empirical counterfactual. That's why we need a large overlap (common support) of the two groups.

The primary advantage of PSM over OLS is that PSM does not have to specify the multi-dimensional relationship between X and the outcome. This way, PSM also reduces bias caused by possible multicolinearity among covariates.

\section{Data and Descriptive Analysis}

\subsection{Survey and data}

The survey in 2013, with a title of "Outstanding Engineer Plan Questionnaire", was conducted by Chinese Academy of Engineering and China's Ministry of Education, and led by researchers at Tsinghua University in Beijing, China. Researchers drew a sample of 2,272 (Note 9) engineers out of 7,428, from six Chinese organizations, among which, one was a listed company, two were large state-owned enterprises and the remaining three were research institutes (one at a province level and two at a city level). As in most engineering firms, this sample is unbalanced with male dominance ( $74.8 \%$ male and $25.2 \%$ female).

Table 2 summarizes the main characteristics of this sample. It is worth noting that the means of dichotomous variables should be interpreted as proportions.

The treatment variable CPT was derived from survey question: "How's your practical training at college?" The answer options include 8 categories (Note 10) by the settings where the practical training took place: 1) school's lab; 2) school's metalworking practical studio; 3) school affiliated factory; 4) small state-owned enterprise; 5) medium and 
large state-owned enterprise; 6) private enterprise; 7) foreign enterprise/joint ventures; and 8) government. Survey results indicated that survey participants were trained in at least one of the above categories. Not all of these categories can count towards CPT. As stated earlier, one of CPT's characteristics is "outside of campus" and only options 4) small state-owned enterprise; 5) medium and large state-owned enterprise; 6) private enterprise; 7) foreign enterprise/joint ventures; and 8) government meet this requirement. Hence, to be included in the treatment group, a student must be enrolled for practical training in any area between options 4) to 8); otherwise they would be counted toward the control/comparison group.

Table 2. Distribution of Sample Characteristics

\begin{tabular}{lrrrrrl}
\hline \multicolumn{1}{c}{ Variable } & N & Mean & $\begin{array}{c}\text { Standard } \\
\text { Deviation }\end{array}$ & Min & Max & Measure \\
\hline Gender & 2,272 & 0.75 & 0.43 & 0 & 1 Male or female \\
Age & 2,249 & 33.97 & 9.01 & 21 & 72 Age at 2012 \\
Education & 2,249 & 3.04 & 0.62 & 1 & 5 Level of education \\
Experience & 2,263 & 12.05 & 10.17 & 1 & 49 Years of working \\
Industry & 2,272 & 0.73 & 0.43 & 0 & 1 Industry or research \\
Professional title & 2,230 & 2.81 & 1.03 & 1 & 6 Level of professionals \\
Father's education & 2,232 & 1.04 & 0.92 & 0 & 4 Level of education \\
Mother's education & 2,226 & 0.71 & 0.78 & 0 & 5 Level of education (Note 11) \\
Residence at age 14 & 2,222 & 4.17 & 1.93 & 1 & 7 Types of residence areas \\
Have a private bedroom & 2,226 & 0.34 & 0.47 & 0 & 1 Yes or no \\
Have Internet at home & 2,235 & 0.20 & 0.40 & 0 & 1 Yes or no \\
Have TV at home & 1,942 & 0.32 & 0.46 & 0 & 1 Yes or no \\
Have laptop & 1,497 & 0.04 & 0.19 & 0 & 1 Yes or no \\
Have radio & 2,146 & 0.21 & 0.32 & 0 & 1 Yes or no \\
Have musical instrument & 1,673 & 0.16 & 0.47 & 0 & 1 Yes or no \\
Have camera & 1,525 & 0.89 & 0.30 & 0 & 1 Yes or no \\
Ranking at high school & 2,197 & 1.83 & 0.92 & 1 & 5 Quartile ranking \\
CPT & 2,272 & 0.69 & 0.46 & 0 & 1 Participated in CPT or not \\
Initial salary per year (Note 12) & 2,147 & 1.81 & 1.77 & 0 & 24 Nominal value in that year \\
\hline
\end{tabular}

There are several reasons why we differentiate outside of campus practice (CPT) and on campus training (control group), and expect that these two types of practice will have different impact on student's workplace outcomes. a) Scale. Facilities in factories and firms were usually in a larger scale compared to on campus labs or studio settings. That way, students that participated in CPT have experience that the control group doesn't have; b) Quality. By the same token, resources and physical plant in factories and firms were up-to-date and provide a more real world experience/work environment. Training instructors were most likely to be workers who were more apt in their field and provided higher quality training. Hence, the quality of practical training in CPT is likely to be higher compared to on campus practices; c) Networking. Aside from gains in skills, outside of campus training also provides opportunities for students to network with workers and managers in firms, which will gain social capital to their career development.

In total, the treatment group consists of 1,580 participants while the control group includes 692 individuals. Among the treated, 1,204 were male while 376 were female with most of the participants doing their CPT in an industry setting $(97 \%)$ and only a small group (3\%) at government setting.

\subsection{Self-reported CPT effectiveness data}

The survey also contains information directly related to the effectiveness of CPT. The questionnaire surveys each engineer's opinions about the effect of CPT on their jobs. These self-reported CPT effect data are in a scale of 1-4: 1) large effect; 2) medium effect; 3) small effect; and 4) no effect. One may use this self-reported effect data as a proxy of 
engineers' personal satisfaction with CPT, rather than the real effect of CPT on their post-college career.

Results show that most engineers (94.2\%) agree that CPT was helpful to their jobs, with only about 6 percent conveying a clear disagreement. This finding is consistent with and adds to the literature (Chen, 1999; Qiao, 2005) about positive effects of CPT. Results are also in line with Dewey's observation that environment affects educational experiences (Dewey, 1938) as the effect does vary by setting. The majority of engineers conducted their CPT at medium and large state-owned enterprises, followed by private enterprise, small state-owned enterprises, with a small group at foreign enterprise/joint ventures and government settings.

Table 3. Self-reported CPT Effect

\begin{tabular}{lrrrr}
\hline & $\begin{array}{c}\text { No } \\
\text { effect } \\
\text { \% (Note 13) }\end{array}$ & $\begin{array}{c}\text { Small effect } \\
\%\end{array}$ & $\begin{array}{c}\text { Medium } \\
\text { effect } \\
\%\end{array}$ & $\begin{array}{c}\text { Large effect } \\
\%\end{array}$ \\
\hline Small state-owned enterprise & 4.7 & 23.3 & 37.7 & 34.3 \\
Medium and large state-owned enterprise & 3.1 & 15.7 & 39.8 & 41.4 \\
Private enterprise & 6.7 & 16.2 & 38.8 & 38.3 \\
Foreign enterprise or joint ventures & 13.3 & 15.8 & 37.1 & 33.8 \\
Government & 17.0 & 23.1 & 33.0 & 26.9 \\
\hline
\end{tabular}

Table 3 summarized the results from the survey. In general, engineers conducting their CPT at medium and large state-owned enterprises were the most satisfied, with more than 80 percent reporting a medium or large effect. The "no effect' proportion was as low as 3 percent. In contrast, the 'no effect' proportion was about 15 percent at foreign enterprise/joint ventures and government settings, which was higher than the other settings. In between were small enterprise and private enterprise, with 'no effect' rates of 5 percent and 7 percent, respectively.

These findings were consistent with the literatures about positive CPT effect in large enterprises (Zhou, 2009; Zou, 2009) and negative CPT effect in small and private enterprises (Cao \& He, 2008; Gou, 2012; Wei, Ye, \& Zhang, 2008).

\subsection{Workplace outcomes}

The survey also reports labor market outcomes related to career development. For instance, earnings refer to the gross before-tax (Note 14) income in 2012, including full-time job salary, part-time job salary, bonus, project allowance, income from technology transfer, etc. The variable earnings was an ordered categorical variable, which was measured by ten income levels ranging from RMB 30,000 to $570,000(\$ 4,886$ to 92,849$)$.

Another variable related to career development was the cumulative amount of funding engineers received from all the projects and programs they have led. This variable can be used as a proxy of engineers' productivity.

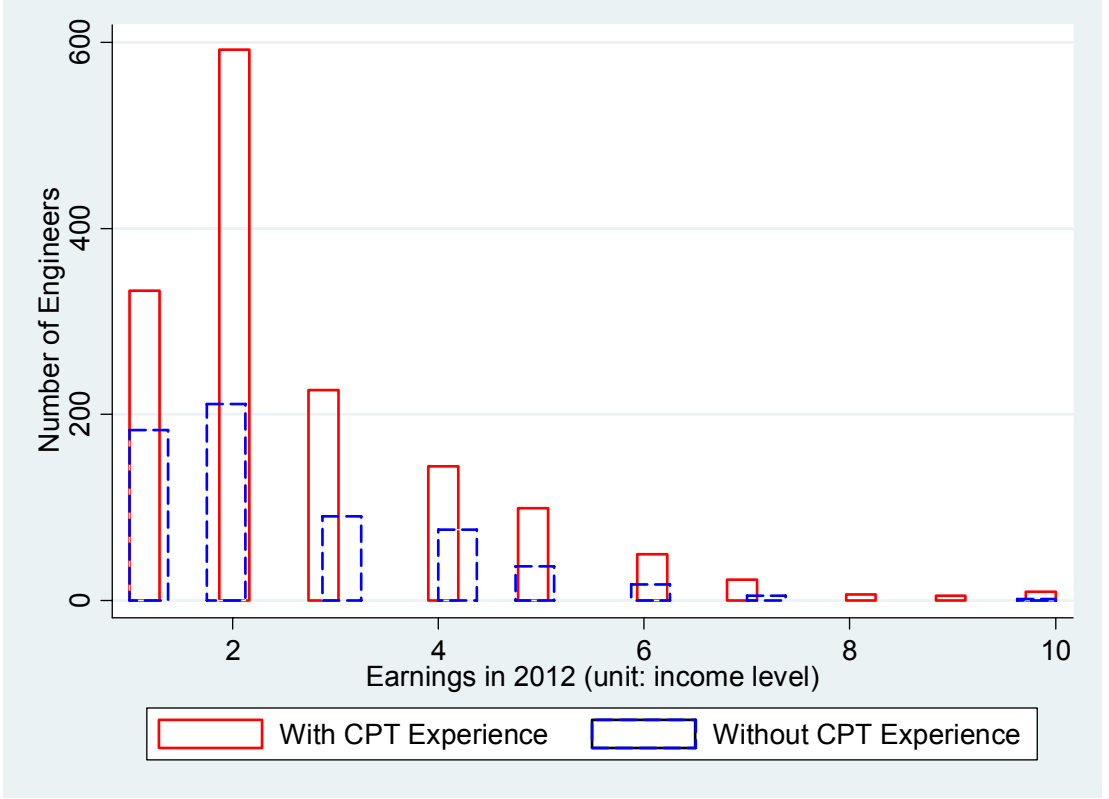

Figure 2. Distribution of earnings (Note 15) 


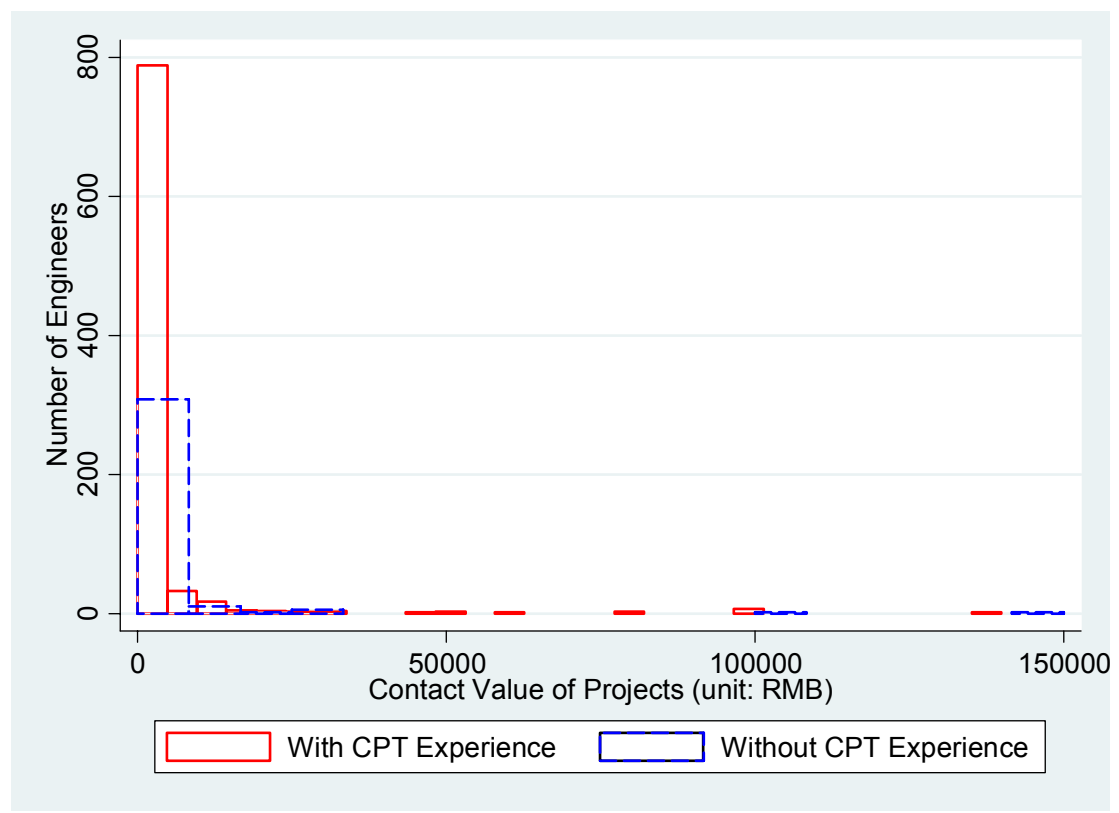

Figure 3. Distribution of productivity

In order to distinguish the difference in career development outcomes between the treated and control, Figures 2 and 3 provide a comparison. In terms of earnings, the treated (those with CPT experience) tend to have higher income levels. However, the difference was more subtle for productivity. In the treatment group, productivity was widely distributed from zero to RMB $14,000(\$ 2,280)$. However, productivity in the control group tends to concentrate towards the lower and higher ends, but not the middle. None of the existing literature has yet captured this phenomenon.

\section{Impacts of CPT on Workplace Outcomes}

In this section, the effects of CPT on an engineer's career development (post-college earnings and productivity) are discussed in several ways. First, the baseline estimates from OLS are reported. Second, the effects are estimated based on Propensity Score Matching. Finally, heterogeneous effects and robust checks of the estimation are examined.

\subsection{Baseline Model (without matching)}

There are two different measures of an engineer's career development. The ordered categorical variable earnings indicates the pecuniary returns to CPT and the continuous variable productivity is used as a proxy for an engineer's performance at work, which may not be returned in pecuniary forms. The covariates involved in these analyses are listed in Table 2, with the descriptive statistics.

Table 4 reports the effects of all the covariates on the whole sample, estimated with ordered probit (for earnings) and OLS (for productivity). The main difference between models are: Models 1 and 4 control for covariates that affect the outcome variable; Models 2 and 5 add working place related covariates; and Models 3 and 6 add pretreatment variables to control for SES and ability. 
Table 4. Regression Results - Baseline Model

\begin{tabular}{|c|c|c|c|c|c|c|}
\hline \multirow{2}{*}{ Dependent Variables: } & \multicolumn{3}{|c|}{ earnings } & \multicolumn{3}{|c|}{ productivity } \\
\hline & (1) & (2) & (3) & (4) & (5) & (6) \\
\hline \multirow{2}{*}{ CPT } & $0.178 * * *$ & $0.189 * * *$ & $0.236 * * *$ & 0.144 & 0.159 & $0.471^{*}$ \\
\hline & $(0.001)$ & $(0.000)$ & $(0.001)$ & $(0.439)$ & $(0.398)$ & $(0.049)$ \\
\hline \multirow[t]{2}{*}{ Age } & - & - & $0.031^{*}$ & - & - & 0.056 \\
\hline & & & $(0.045)$ & & & $(0.356)$ \\
\hline \multirow[t]{2}{*}{ Initial earnings } & $0.128 * * *$ & $0.135^{* * *}$ & $0.175 * * *$ & -0.016 & -0.011 & -0.128 \\
\hline & $(0.000)$ & $(0.000)$ & $(0.000)$ & $(0.731)$ & $(0.809)$ & $(0.111)$ \\
\hline \multirow[t]{2}{*}{ Education } & $0.629 * * *$ & $0.636^{* * *}$ & $0.607 * * *$ & $0.455^{* * *}$ & 0.565 & -0.110 \\
\hline & $(0.000)$ & $(0.000)$ & $(0.000)$ & $(0.004)$ & $(0.155)$ & $(0.612)$ \\
\hline \multirow[t]{2}{*}{ Experience } & $0.138 * * *$ & $0.098 * * *$ & $0.092 * * *$ & $0.199 * * *$ & $0.126 * *$ & 0.059 \\
\hline & $(0.000)$ & $(0.000)$ & $(0.000)$ & $(0.000)$ & $(0.013)$ & $(0.474)$ \\
\hline \multirow[t]{2}{*}{$(\text { Experience })^{2}$} & $-0.003 * * *$ & $-0.002 * * *$ & $-0.003 * * *$ & $-0.004 * * *$ & $-0.002 * *$ & $-0.002 * *$ \\
\hline & $(0.000)$ & $(0.000)$ & $(0.000)$ & $(0.000)$ & $(0.035)$ & $(0.080)$ \\
\hline \multirow[t]{2}{*}{ Industry } & $-0.652 * * *$ & $-0.623 * * *$ & $-0.665 * * *$ & $-0.913 * * *$ & $-0.820 * * *$ & $-1.015^{* * *}$ \\
\hline & $(0.000)$ & $(0.000)$ & $(0.000)$ & $(0.000)$ & $(0.000)$ & $(0.000)$ \\
\hline \multirow{2}{*}{ Professional title } & $0.264 * * *$ & $0.250 * * *$ & $0.275^{* * *}$ & $0.416^{* * *}$ & $0.397 * * *$ & $0.476^{* * *}$ \\
\hline & $(0.000)$ & $(0.000)$ & $(0.000)$ & $(0.001)$ & $(0.002)$ & $(0.002)$ \\
\hline \multirow[t]{2}{*}{ Company experience } & - & $0.061 * * *$ & $0.088 * * *$ & - & $0.118^{* *}$ & $0.107 *$ \\
\hline & & $(0.000)$ & $(0.000)$ & & $(0.019)$ & $(0.096)$ \\
\hline \multirow[t]{2}{*}{ (Company experience) $^{2}$} & - & $-0.001 * *$ & $-0.002 * * *$ & - & $-0.003^{*}$ & $-0.003 *$ \\
\hline & & $(0.014)$ & $(0.003)$ & & $(0.049)$ & $(0.083)$ \\
\hline \multirow[t]{2}{*}{ Residence at age 14} & - & - & $-0.052 * * *$ & - & - & $-0.140 * *$ \\
\hline & & & $(0.007)$ & & & $(0.026)$ \\
\hline \multirow[t]{2}{*}{ Have a private bedroom } & - & - & 0.081 & - & - & -0.159 \\
\hline & & & $(0.255)$ & & & $(0.487)$ \\
\hline \multirow[t]{2}{*}{ Have Internet at home } & - & - & $0.227^{* *}$ & - & - & -0.115 \\
\hline & & & $(0.012)$ & & & $(0.681)$ \\
\hline \multirow[t]{2}{*}{ Have TV at home } & - & - & $-0.165^{*}$ & - & - & $-0.415^{*}$ \\
\hline & & & $(0.036)$ & & & $(0.095)$ \\
\hline \multirow[t]{2}{*}{ Have laptop } & - & - & 0.084 & - & - & -0.000 \\
\hline & & & $(0.653)$ & & & $(1.000)$ \\
\hline \multirow[t]{2}{*}{ Have radio } & - & - & $0.179^{*}$ & - & - & 0.411 \\
\hline & & & $(0.060)$ & & & $(0.181)$ \\
\hline \multirow[t]{2}{*}{ Have musical instrument } & - & - & $0.350 * * *$ & - & - & 0.251 \\
\hline & & & $(0.000)$ & & & $(0.303)$ \\
\hline \multirow[t]{2}{*}{ Have camera } & - & - & $-0.251^{*}$ & - & - & $-0.833 * *$ \\
\hline & & & $(0.043)$ & & & $(0.048)$ \\
\hline \multirow[t]{2}{*}{ Ranking at high school } & - & - & -0.011 & - & - & $-0.328 * * *$ \\
\hline & & & $(0.748)$ & & & $(0.003)$ \\
\hline $\mathbf{N}$ & 2,017 & 2,006 & 1,204 & 751 & 745 & 465 \\
\hline R squared & - & - & - & 0.191 & 0.198 & 0.306 \\
\hline Pseudo R squared & 0.1376 & 0.143 & 0.184 & - & - & - \\
\hline Prob $>$ chi 2 & 0 & 0 & 0 & - & - & - \\
\hline
\end{tabular}

Note: a) $* * * \mathrm{p}<0.01, * * \mathrm{p}<0.05, * \mathrm{p}<0.1 ; \mathrm{b})$ Standard errors are in parenthesis; $\mathrm{c})$ Earnings is an ordered categorical variable, so ordered probit is used to estimate the coefficient; d) Productivity variable is in log term and coefficient is estimated with OLS; e) by 'age', it refers to the age of year 2013, not the age when the participant received the treatment, so the age effect may be better interpreted as a cohort effect. 
Model (3) of Table 4 shows that CPT has a statistically significant positive contribution to future earnings. Other significant and positive determinants were CPT, age, initial earnings, education, experience, professional title, experience at the current company, residence at age 14, having access to internet, radio, musical instrument, or camera at age 14. In contrast, working in the industry (rather than research institutes), having tv and camera at home at age 14 are negative determinants of future earnings.

For productivity, Model (6) of Table 4 shows that CPT and professional title were significant positive determinants, while working in the industry (rather than research institutes), residence at age 14, having a tv or camera at age 14, and academic performance rankings at high school are negative determinants of productivity.

\subsection{With Matching (PSM Model) (Note 16)}

The critical task for propensity-score matching was to find a balanced model. As a rule of thumb, criteria for balance check in this research were: 1 ) for continuous variable, the difference in means to be less than or equal to 0.05 treatment group standard deviations and the ratio of standard deviations to be between 0.91 and $1.1 ; 2$ ) for binary/indicator variables, the difference in percentage across groups to be less than or equal to 0.025 . Table 5 summarizes the balance check for each covariate. Overall, this model satisfies all the balance criteria.

Table 5. Propensity Score Matching Balance Check

\begin{tabular}{|c|c|c|c|c|c|c|c|c|}
\hline \multirow{2}{*}{ Variable } & \multirow{2}{*}{ Sample } & \multicolumn{2}{|c|}{ Mean } & \multicolumn{2}{|c|}{ SD } & \multirow{2}{*}{$\begin{array}{l}\text { STD } \\
\text { Diff }\end{array}$} & \multirow{2}{*}{$\begin{array}{l}\text { Ratio } \\
\text { of SDs }\end{array}$} & \multirow{2}{*}{$\begin{array}{l}\text { Diff } \\
\text { in \% }\end{array}$} \\
\hline & & Treated & Control & Treated & Control & & & \\
\hline \multirow[t]{2}{*}{ Age } & Unmatched & 32.453 & 35.162 & 8.77 & 9.54 & -0.309 & 0.92 & \\
\hline & Matched & 32.453 & 32.57 & 8.77 & 8.33 & -0.013 & 1.05 & \\
\hline \multirow[t]{2}{*}{ male } & Unmatched & 0.788 & 0.719 & 0.41 & 0.45 & 0.167 & 0.91 & \\
\hline & Matched & 0.788 & 0.81 & 0.41 & 0.39 & -0.055 & 1.04 & -0.022 \\
\hline \multirow[t]{2}{*}{ grad } & Unmatched & 0.186 & 0.162 & 0.39 & 0.37 & 0.061 & 1.05 & \\
\hline & Matched & 0.186 & 0.17 & 0.39 & 0.38 & 0.042 & 1.04 & 0.016 \\
\hline \multirow[t]{2}{*}{ bachelor } & Unmatched & 0.285 & 0.327 & 0.45 & 0.47 & -0.093 & 0.96 & \\
\hline & Matched & 0.285 & 0.261 & 0.45 & 0.44 & 0.054 & 1.03 & 0.024 \\
\hline \multirow[t]{2}{*}{ dad_eng } & Unmatched & 0.201 & 0.276 & 0.4 & 0.45 & -0.187 & 0.9 & \\
\hline & Matched & 0.201 & 0.176 & 0.4 & 0.38 & 0.063 & 1.05 & 0.025 \\
\hline \multirow[t]{2}{*}{ dad_pro } & Unmatched & 0.175 & 0.209 & 0.38 & 0.41 & -0.09 & 0.93 & \\
\hline & Matched & 0.175 & 0.199 & 0.38 & 0.4 & -0.064 & 0.95 & -0.024 \\
\hline \multirow[t]{2}{*}{ dad_army } & Unmatched & 0.005 & 0.01 & 0.07 & 0.1 & -0.079 & 0.69 & \\
\hline & Matched & 0.005 & 0.006 & 0.07 & 0.08 & -0.014 & 0.91 & -0.001 \\
\hline \multirow[t]{2}{*}{ dad_service } & Unmatched & 0.072 & 0.036 & 0.26 & 0.19 & 0.138 & 1.38 & \\
\hline & Matched & 0.072 & 0.071 & 0.26 & 0.26 & 0.004 & 1 & 0.001 \\
\hline \multirow[t]{2}{*}{ dad_gov } & Unmatched & 0.093 & 0.093 & 0.29 & 0.29 & 0.001 & 1 & \\
\hline & Matched & 0.093 & 0.104 & 0.29 & 0.31 & -0.037 & 0.95 & -0.011 \\
\hline \multirow[t]{2}{*}{ dad_unem } & Unmatched & 0.043 & 0.036 & 0.2 & 0.19 & 0.033 & 1.08 & \\
\hline & Matched & 0.043 & 0.045 & 0.2 & 0.21 & -0.01 & 0.98 & -0.002 \\
\hline \multirow[t]{2}{*}{ urban } & Unmatched & 0.425 & 0.464 & 0.49 & 0.5 & -0.079 & 0.99 & \\
\hline & Matched & 0.425 & 0.427 & 0.49 & 0.5 & -0.004 & 1 & -0.002 \\
\hline \multirow[t]{2}{*}{ bedroom } & Unmatched & 1.641 & 1.704 & 0.48 & 0.46 & -0.13 & 1.05 & \\
\hline & Matched & 1.641 & 1.662 & 0.48 & 0.47 & -0.044 & 1.01 & -0.021 \\
\hline \multirow[t]{2}{*}{ internet } & Unmatched & 1.819 & 1.802 & 0.39 & 0.4 & 0.044 & 0.97 & \\
\hline & Matched & 1.819 & 1.821 & 0.39 & 0.38 & -0.005 & 1 & -0.002 \\
\hline
\end{tabular}




\begin{tabular}{lllrrrrrr}
\hline tv & Unmatched & 1.613 & 1.557 & 0.49 & 0.5 & 0.116 & 0.98 & \\
\hline laptop & Matched & 1.613 & 1.613 & 0.49 & 0.49 & 0 & 1 & 0 \\
\hline Unmatched & 1.043 & 1.018 & 0.2 & 0.13 & 0.122 & 1.52 & \\
\hline radio & Matched & 1.043 & 1.044 & 0.2 & 0.2 & -0.005 & 0.99 & -0.001 \\
\hline & Unmatched & 1.864 & 1.835 & 0.34 & 0.37 & 0.085 & 0.92 & \\
\hline instrument & Matched & 1.864 & 1.86 & 0.34 & 0.35 & 0.011 & 0.99 & 0.004 \\
\hline & Unmatched & 1.284 & 1.216 & 0.45 & 0.41 & 0.15 & 1.09 & \\
\hline camera & Matched & 1.284 & 1.27 & 0.45 & 0.44 & 0.032 & 1.01 & 0.014 \\
\hline & Unmatched & 1.093 & 1.062 & 0.29 & 0.24 & 0.108 & 1.21 & \\
\hline ranking1 & Matched & 1.093 & 1.098 & 0.29 & 0.3 & -0.017 & 0.98 & -0.005 \\
\hline & Unmatched & 0.469 & 0.448 & 0.5 & 0.5 & 0.042 & 1 & \\
\hline ranking2 & Unmatched & 0.469 & 0.45 & 0.5 & 0.5 & 0.039 & 1 & 0.019 \\
\hline & Matched & 0.315 & 0.314 & 0.46 & 0.46 & 0.002 & 1 & \\
\hline ranking3 & Unmatched & 0.315 & 0.303 & 0.46 & 0.46 & 0.027 & 1.01 & 0.012 \\
\hline & Matched & 0.152 & 0.157 & 0.36 & 0.36 & -0.014 & 0.99 & \\
\hline ranking4 & Unmatched & 0.037 & 0.041 & 0.19 & 0.2 & -0.023 & 0.95 & \\
\hline & Matched & 0.037 & 0.037 & 0.19 & 0.19 & 0 & 1 & 0 \\
\hline
\end{tabular}

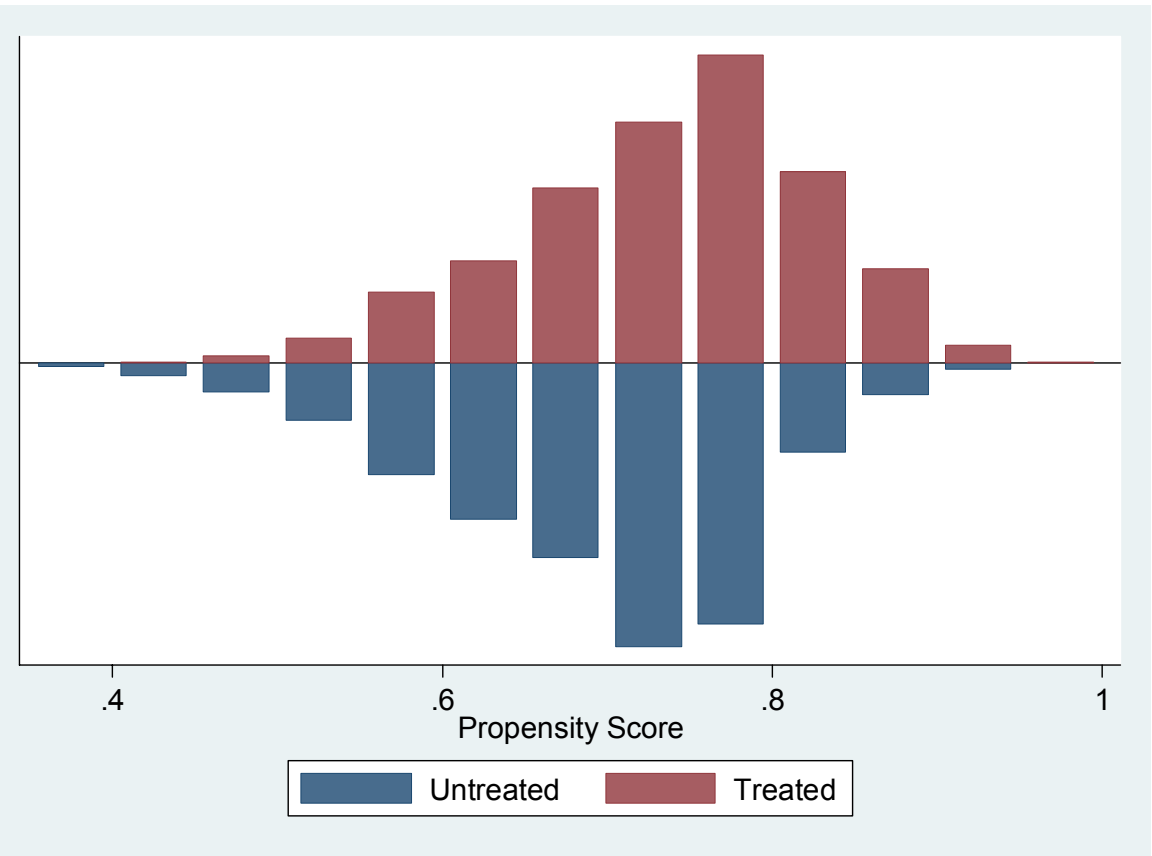

Figure 4. Propensity Score Matching Common Support Check

Another factor that influences the matching results is the common support. Ultimately, the more overlapping between the two groups, the better the match will be. As Figure 4 indicates, treatment and control groups share a large area of common support.

\section{a) Coefficient}

As Table 6 indicates, the coefficient of CPT is not statistically significant for earnings but significant for productivity. The interpretation of coefficient in the productivity model is straight forward: participating in CPT increases an engineer's productivity by 61.7 percent. And the coefficient in earnings model cannot be interpreted as in OLS. We will discuss them with marginal effect. 
Table 6. Regression Results (PSM Model)

\begin{tabular}{|c|c|c|c|}
\hline \multirow[t]{2}{*}{ Dependent Variables: } & \multicolumn{2}{|c|}{$\begin{array}{c}\text { earnings } \\
\text { (1) }\end{array}$} & \multirow{2}{*}{$\begin{array}{c}\text { productivity } \\
\text { (2) } \\
\text { Coefficient }\end{array}$} \\
\hline & Coefficient & Marginal Effect & \\
\hline \multirow[t]{2}{*}{ CPT } & 0.135 & 0.021 & $0.617 * *$ \\
\hline & $(0.149)$ & $(0.407)$ & $(0.041)$ \\
\hline \multirow[t]{2}{*}{ age } & $0.048 * * *$ & $0.014 * * *$ & $0.094 * * *$ \\
\hline & $(0.000)$ & $(0.000)$ & $(0.000)$ \\
\hline \multirow[t]{2}{*}{ male } & $0.160^{*}$ & $0.043 *$ & 0.330 \\
\hline & $(0.110)$ & $(0.068)$ & $(0.329)$ \\
\hline \multirow[t]{2}{*}{ graduate } & $1.655 * * *$ & $0.454 * * *$ & $1.124 * *$ \\
\hline & $(0.000)$ & $(0.000)$ & $(0.025)$ \\
\hline \multirow[t]{2}{*}{ bachelor } & $-0.575 * * *$ & $0.202 * * *$ & -0.406 \\
\hline & $(0.000)$ & $(0.000)$ & $(0.430)$ \\
\hline \multirow[t]{2}{*}{ dad_engineer } & -0.203 & $0.117 * * *$ & -0.174 \\
\hline & $(0.155)$ & $(0.001)$ & $(0.726)$ \\
\hline \multirow[t]{2}{*}{ dad_pro } & $0.102 * *$ & 0.048 & -0.472 \\
\hline & $(0.498)$ & $(0.221)$ & $(0.376)$ \\
\hline \multirow[t]{2}{*}{ dad_army } & 0.536 & -0.004 & 0.843 \\
\hline & $(0.368)$ & $(0.974)$ & $(0.160)$ \\
\hline \multirow[t]{2}{*}{ dad_service } & $0.308 * *$ & -0.001 & 0.184 \\
\hline & $(0.038)$ & $(0.973)$ & $(0.725)$ \\
\hline \multirow[t]{2}{*}{ dad_gov } & $0.326^{*}$ & 0.038 & -0.625 \\
\hline & $(0.083)$ & $(0.483)$ & $(0.176)$ \\
\hline \multirow[t]{2}{*}{ dad_unemploy } & 0.208 & 0.035 & 0.050 \\
\hline & $(0.298)$ & $(0.616)$ & $(0.934)$ \\
\hline \multirow[t]{2}{*}{ urban } & 0.072 & 0,594 & 1.648 \\
\hline & $(0.889)$ & $(0.101)$ & $(0.142)$ \\
\hline \multirow[t]{2}{*}{ bedroom } & -0.024 & 0.000 & 0.036 \\
\hline & $(0.821)$ & $(0.983)$ & $(0.898)$ \\
\hline \multirow[t]{2}{*}{ internet } & 0.037 & -0.019 & -0.408 \\
\hline & $(0.782)$ & $(0.572)$ & $(0.238)$ \\
\hline \multirow[t]{2}{*}{ tv } & $-0.237 * *$ & 0.040 & -0.037 \\
\hline & $(0.031)$ & $(0.197)$ & $(0.906)$ \\
\hline \multirow[t]{2}{*}{ laptop } & -0.023 & 0.091 & 0.397 \\
\hline & $(0.940)$ & $(0.283)$ & $(0.637)$ \\
\hline \multirow[t]{2}{*}{ radio } & 0.231 & $-0.071^{*}$ & -0.430 \\
\hline & $(0.115)$ & $(0.054)$ & $(0.249)$ \\
\hline \multirow[t]{2}{*}{ instrument } & 0.122 & $-0.066^{*}$ & $1.070 * * *$ \\
\hline & $(0.317)$ & $(0.065)$ & $(0.002)$ \\
\hline \multirow[t]{2}{*}{ camera } & -0.166 & 0.045 & -0.599 \\
\hline & $(0.462)$ & $(0.359)$ & $(0.215)$ \\
\hline \multirow[t]{2}{*}{ ranking1 } & -0.194 & -0.099 & $1.638 * * *$ \\
\hline & $(0.657)$ & $(0.250)$ & $(0.008)$ \\
\hline \multirow[t]{2}{*}{ ranking2 } & -0.052 & -0.112 & $1.600 * * *$ \\
\hline & $(0.906)$ & $(0.195)$ & $(0.010)$ \\
\hline ranking3 & -0.339 & -0.064 & $1.357^{* *}$ \\
\hline
\end{tabular}




\begin{tabular}{|c|c|c|c|}
\hline \multirow{3}{*}{ ranking4 } & $(0.452)$ & $(0.480)$ & $(0.045)$ \\
\hline & -0.021 & -0.136 & $1.585^{* *}$ \\
\hline & $(0.964)$ & $(0.179)$ & $(0.042)$ \\
\hline Constant & \multicolumn{2}{|c|}{-} & -1.208 \\
\hline $\mathbf{N}$ & \multicolumn{2}{|c|}{1,232} & 461 \\
\hline R squared & \multicolumn{2}{|c|}{-} & 0.211 \\
\hline Pseudo R squared & \multicolumn{2}{|c|}{0.102} & - \\
\hline Prob $>$ chi 2 & \multicolumn{2}{|c|}{0} & - \\
\hline
\end{tabular}

Note: a) ${ }^{* * *} \mathrm{p}<0.01,{ }^{* *} \mathrm{p}<0.05,{ }^{*} \mathrm{p}<0.1$; b) Standard errors are in parenthesis; c) earnings is an ordered categorical variable, so ordered probit was used to estimate the coefficient; d) productivity variable was in log term and coefficient was estimated with OLS.

\section{b) Marginal effect and model based prediction}

The marginal effect reported in Table 6 was the average marginal effect (AME). That means that the marginal effect of CPT (0.021) was estimated when all the covariate were at their means. Since the mean of dummy variables (i.e., being $80 \%$ male) doesn't mean anything in real life, we use model based prediction to interpret the effect.

For example, a 30 years old male with a bachelor degree, a father who is an engineer, was raised in a rural area, owned a private bedroom, laptop, radio, musical instrument, camera, access to internet at 14 , and was ranked in the top $10 \%$ at high school. What's the effect of CPT on the probability of him/her having an income of RMB 50,000-70,000 $(\$ 8,051-11,272)$ in 2012 ? First, we calculate the marginal effect when CPT $=1$. In this scenario, the effect is 0.08 . Next, we calculate the marginal effect when $\mathrm{CPT}=0$, which is 0.07 . Finally, we take the difference between 0.0006 and 0.0004. This 0.01 difference is the treatment effect of CPT on this person's earnings. In plain language, participating in CPT increases this person's probability of an income of RMB 50,000-70,000 $(\$ 8,051-11,272)$ (Note 17) in 2012 by 0.01 . In this specific case, the treatment effect is small but significant.

\section{c) The mean of the average treatment effect}

Table 7. Corrected Standard Errors with Bootstrap ( $\mathrm{Y}=$ earnings)

\begin{tabular}{lcclcccl}
\hline Variable & Reps & Observed & Bias & Std. Err. & \multicolumn{2}{c}{ [95\% Conf. Interval] } \\
\hline${ }_{-}{ }^{-} \_1$ & 1,000 & 0.252 & -0.128 & 0.150 & -0.041 & 0.546 & $(\mathrm{~N})$ \\
& & & & & -0.193 & 0.402 & $(\mathrm{P})$ \\
& & & & & 0.085 & 0.546 & (BC) \\
\hline
\end{tabular}

Note: $\mathrm{N}=$ normal; $\mathrm{P}=$ percentile; $\mathrm{BC}=$ bias-corrected

Table 8. Corrected Standard Errors with Bootstrap (Y=productivity)

\begin{tabular}{lcclcccl}
\hline Variable & Reps & Observed & Bias & Std. Err. & \multicolumn{3}{c}{ [95\% Conf. Interval] } \\
\hline${ }_{-}{ }^{-} \_1$ & 1,000 & 0.375 & -0.216 & 0.387 & -0.385 & 1.135 & $(\mathrm{~N})$ \\
& & & & & -0.625 & 0.905 & $(\mathrm{P})$ \\
& & & & & -0.169 & 1.243 & $(\mathrm{BC})$ \\
\hline
\end{tabular}

Note: $\mathrm{N}=$ normal; $\mathrm{P}=$ percentile; $\mathrm{BC}=$ bias-corrected

We use bootstrap to simulate the matching procedure for 1,000 times to get the distribution of the estimand (ATT). The mean of the estimate of ATT on earnings is 0.252 and that on productivity is 0.375 .

In general, CPT has a small positive effect on earnings while the effect size is very small when propensity score is around 0.8 . In contrast, CPT has a negative effect on productivity when propensity score is lower than 0.6 . The effect turns out to be positive as propensity score goes up and beyond 0.6 and gradually diminish towards the high end (propensity score reaches 0.9 and above).

\subsection{Heterogeneous effects and robustness check}

\section{a) Heterogeneous effects on earnings}

For heterogeneity analysis, we first look at the effect of CPT against an engineer's age when they received the survey. As Figure 5 indicates that after an initial increase, the effect of CPT on earnings reaches its peak at age 46 and declines as age increases. 


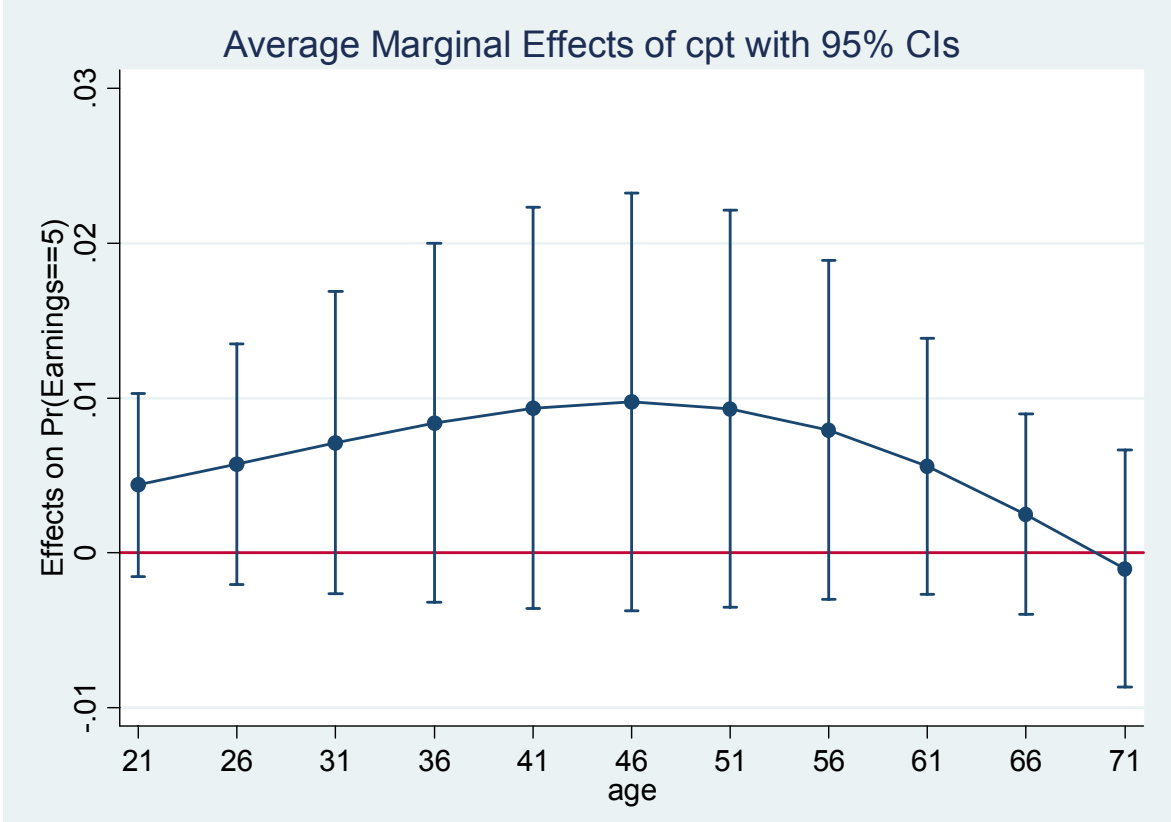

Figure 5. Effect of CPT depending on age

Then, we compared the effects by male vs. female, rural vs. urban, and whether father is an engineer groups, using the same scenario as in previous discussion of marginal effect. All these three pair differences are statistically significant.

Table 9. Heterogeneous Effects on Earnings

\begin{tabular}{ccc}
\hline Pair & CPT's Effect on Earnings & Pair Difference \\
\hline Male & 0.01 & $0.002^{* * *}$ \\
Female & 0.008 & \\
Rural & 0.01 & $0.001^{* *}$ \\
Urban & 0.009 & \\
dad_is an engineer & 0.01 & $0.001^{* *}$ \\
dad_not an_engineer & 0.009 & \\
\hline
\end{tabular}

Note: $* * * p<0.01,{ }^{* *} \mathrm{p}<0.05,{ }^{*} \mathrm{p}<0.1$

Lastly, we examined the above three pair differences across age groups. Overall, the magnitude of these differences was quite small across all age groups. Interestingly, the effect of CPT for female overweighs that for male. This may relate to China's retirement system. Women retire at age 55 and men retire at 60 . If a female engineer continues to work after retirement, she must have exceptional skill sets and those skills were possibly gained from CPT training in college.

In summary, the effect of CPT on earnings was heterogeneous in several ways. CPT has larger effect on male students than female students, on rural students than urban students, and on students whose father was an engineer than students whose father was not an engineer. Furthermore, the heterogeneous effects vary across age groups.

\section{b) Heterogeneous effects on productivity}

Since productivity is a continuous variable, heterogeneous effects can be captured using three interaction terms: cpt\&male, cpt\&rural, and cpt\&dad_is an engineer. 
Table 10. Heterogeneous Effects on Productivity

\begin{tabular}{ccc}
\hline Pair & CPT's Effect on Productivity & Pair Difference \\
\hline Male & 0.498 & 0.291 \\
Female & 0.207 & \\
Rural & 0.239 & 0.032 \\
Urban & 0.207 & \\
dad_is an engineer & 1.351 & 1.144 \\
dad_not an_engineer & 0.207 &
\end{tabular}

Table 10 summarizes the different effects of CPT on productivity depending on male vs. female, rural vs. urban, and whether father is an engineer groups. Overall, CPT's effect on productivity was larger for male engineers who lived in rural areas when they were 14, especially if their father was an engineer. However with regards to this study, the differences were not significant.

\section{c) Robustness check}

As for robustness check, the main concern is the assumption of equal intervals between ordinal categories in ordered probit regression because the outcome variable earnings in the sample don't hold that assumption. The intervals between ordinal categories of earnings vary from RMB 20,000 to 120,000. One way to check for robustness is to split the whole sample into three subsamples: 1) interval=RMB 20,000; 2) interval=RMB 40,000-90,000; and 3) interval=RMB 120,000. For each subsample, we repeat propensity score matching and regression. The results were quite similar to those from the whole sample. Another way is to use the mid-point of each income level and repeat the entire process, the results were very similar: without matching, CPT has a statistically significant positive contribution to future earnings. However, the statistical significance vanishes after matching.

\section{Discussion and conclusion}

\subsection{Findings}

To conclude, this research demonstrates the following results from the engineer survey in China regarding the effect of CPT on the post-college career development of engineering students.

First, based on a self-reported measure, the survey showed that most of the engineering students were satisfied with their CPT. This means that most engineers are satisfied with their CPT and value this hands-on training experience. More specifically, engineering students who conducted their CPT at medium and large state-owned enterprises were the most satisfied. In contrast, engineering students who conducted their CPT at foreign enterprise/joint ventures and government reported a relatively low satisfaction. These revelations of heterogeneous effects were consistent with previous studies. One plausible explanation for the high satisfaction with CPT at medium and large state-owned enterprise was that in one hand, state-owned enterprises were relatively less profit-oriented than private firms. Therefore, they were more accommodating to students. On the other hand, students also have more access to up-to-date technology and skills in medium and large enterprises than in small firms.

Second, with regards to future earnings, this study found that without matching, CPT had a statistically significant positive contribution to future earnings. However, the statistical significance vanished after matching. With propensity score matching, the average marginal effect of CPT on future earnings was 0.021 . More specifically, for an engineer who is a 30 year old male with a bachelor degree, a father who is an engineer, was raised in a rural area, owned a private bedroom, laptop, radio, musical instrument, camera, access to internet at 14, and was ranked in the top $10 \%$ at high school, participating in CPT increased this person's probability of an income of RMB 450,000-570,000 $(\$ 73,301-92,849)$ in 2012 by 0.0002 . The loss of significance after matching may be due to the endogeneity that comes from the institutional level. The confounding covariates used for matching were all pre-treatment and at individual level, therefore, matching can only control for the endogeneity at individual level but not the institutional level.

Third, in terms of productivity, CPT remains a significant positive determinant with and without matching. Results with propensity score matching indicated that participating in CPT increases an engineer's productivity by 61.7 percent and the mean of effect size is about 37.5 percent. The significance remains across models because productivity was a long run cumulative measure. Hence, this measure captures the effect of CPT on career development over time.

Fourth and last, the effect of CPT on earnings was heterogeneous in several ways. CPT had a larger effect on male students than female students, on rural students than urban students, and on students with an engineer father than students whose father was not an engineer. 


\subsection{Implications}

Based on the generally positive findings of CPT's effect on career development, this research gives several tentative policy suggestions for students, institutions, and the industry.

Students should be motivated to attend CPT. One way to do this is to inform students about the positive effect of CPT on their career development and motivate students with role models. Therefore, colleges and universities should invite alumni to give a speech or have a discussion with students about their expectation of CPT and how to link CPT towards a successful career path. If possible, students can receive mentoring/coaching from alumni prior to attending CPT. Since the research found that CPT has positive effect on long-term labor market outcomes, it's better to prepare students with information to align them with their long term vision toward career goals. The bottom line is that students need to know why CPT is important to them and in what way.

At the institutional level, colleges and universities can continue to provide sufficient funding to CPT because CPT is valuable. To be fair in professor's performance review, professors who lead CPT should be recognized for their time and effort. And in terms of curriculum, there are several options that colleges and universities can choose to modify their curriculum.

a) Make CPT optional. If students are allow to select into CPT, only those who have the desire to pursue an engineering career will participate in CPT. Therefore, these students should be motivated to attend CPT. If that's the case, colleges and universities won't have to worry about attitude issues.

b) Allow students to select their CPT. As the research found students with a father who is an engineer tends to benefit more from CPT, colleges and universities can opt to allow student to use their family ties and network to contact firms. That way, only students who want schools to assign a place for them will participate in the CPT organized by the institution. Hence, the total educational cost of CPT will decrease.

Alternatively, colleges and universities that cannot alter the curriculum (i.e., military institutions) can opt to change their grading system of CPT. The current grading includes 40 percent exam, 40 percent final report, and 20 percent from attendance. As previous studies revealed, students copy and paste reports from online papers, this 40 percent final report grade cannot indicate what students learned from CPT (Cao \& He, 2008; Guo, 2012). Thus, colleges and universities can replace a final report with a daily log or weekly performance review similar to the process done in the industries.

For industries, firms can include campus recruitment plan into CPT. That way, students who participate in CPT will be better oriented to firm's specific demand and requirements. Therefore, firms won't have to worry too much about business intelligence and operation routines. Also, firms can benefit from the large talent pool and early selection process.

\subsection{Limitations and suggestions for further research}

There are several limitations of this study. First, the data used by this study was collected from a few organizations, which may undermine the external validity of the results. However, it is important to notice that regarding the six organizations, the findings were still applicable as a large engineer population was sampled.

Second, this research only studies the impact of CPT in terms of participation, but does not consider the length of CPT into the analysis. Although this study has tried to collect CPT duration by setting, it is difficult to define a good measure due to the heterogeneity among the settings.

Third, this research does not take the quality of CPT into account. Although the survey contains self-reported satisfaction data from engineers, it is difficult to measure the quality of CPT without getting feedback from institutions and industries. Thus, this study omitted the potential heterogeneous effects due to various CPT qualities.

Based on this research, further studies could contribute to the scholarship in this area in at least three aspects. First, since firms surveyed in this study were all in public sector, the research should be replicated in other organizations such as firms in private sectors in China or other countries in order to improve the external validity of the conclusion. In the future survey, the sample can include private enterprise, foreign firms and joint ventures.

Next, the length of CPT should be taken into account. Further studies can either add CPT duration instrument in the survey or conduct PSM and regression on the stratified population by setting.

Finally, the measure of CPT quality should be studied. Qualitative research methods such as interviews can be used in future? studies to better understand how CPT was conducted and perceived. 


\section{Acknowledgement}

This research is supported by Humanities and Social Sciences Fund from China Ministry of Education (No.11JGC024) and Center on Chinese Education at Teachers College, Columbia University.

\section{References}

Becker, G. S. (1967). Human Capital: A Theoretical and Empirical Analysis, with Special Reference to Education. Chicago: University of Chicago Press.

Borjas, G. J. (2005). Labor Economics (3rd edition.). Boston: McGraw-Hill.

Bound, J., \& Solon, G. (1999). Double trouble: on the value of twins-based estimation of the return to schooling. Economics of Education Review, 18(2), 169-182. http://dx.doi.org/10.1016/S0272-7757(98)00048-X

Callahan, D., \& Pedigo, B. (2002). Educating experienced IT professionals by addressing industry's needs. IEEE Software, 19(5), 57-62. http://dx.doi.org/10.1109/MS.2002.1032855

Cao, X.X., \& He, X.F. (2008). Practical Training Problems and Suggestions to Post-secondary Engineering Education. Journal of Chongqing University of Science and Technology (Social Sciences Edition), (04), 194.

Carnoy, M. (1995). Economics of Education. Then and Now, in International Encyclopaedia of Economics of Education, Carnoy M.(ed.), 1-7.

Chen, Y., Li, G., Ying, H., \& Shi, Z. (1999). Reform of practical training in civil engineering education. Journal of Architectural Education in Institutions of Higher Learning, 3.

Dewey, J. (1938). Experience and Education (33rd edition). Macmillan.

Duan, H.F., \& Chen, X.B. (2013). Discussion about How to Improve the Effectiveness of Metalworking Practice. Science and Technology Innovation Herald, (06), 192-193.

Gault, J., Redington, J., \& Schlager, T. (2000). Undergraduate Business Internships and Career Success: Are They Related? Journal of Marketing Education, 22(1), 45-53. http://dx.doi.org/10.1177/0273475300221006

Gelman, A., \& Hill, J. (2006). Data Analysis Using Regression and Multilevel/Hierarchical Models (1 edition.). Cambridge ; New York: Cambridge University Press. http://dx.doi.org/10.1017/CBO9780511790942

Gorman, M. E., Johnson, V. S., Ben-Arieh, D., Bhattacharyya, S., Eberhart, S., Glower, J., ... Wang, Y. M. (2001). Transforming the Engineering Curriculum: Lessons Learned from a Summer at Boeing. Journal of Engineering Education, 90(1), 143-149. http://dx.doi.org/10.1002/j.2168-9830.2001.tb00582.x

Griliches, Z., \& Mason, W. M. (1972). Education, income, and ability. The Journal of Political Economy, 74-103. http://dx.doi.org/10.1086/259988

Grubbström, R. W. (1967). On the Application of the Laplace Transform to Certain Economic Problems. Management Science, 13(7), 558-567. http://dx.doi.org/10.1287/mnsc.13.7.558

Guo, Y. (2012). Problems and Solution to Practical Training in Engineering Education. China Education Innovation Herald, (13), 149.

Guo, S. Y., \& Fraser, M. W. (2010). Propensity Score Analysis: Statistical Methods and Applications (1 edition.). Thousand Oaks, California: SAGE Publications, Inc.

Heitmann, G. (2005). Challenges of engineering education and curriculum development in the context of the Bologna process. European Journal of Engineering Education, 30(4), 447-458. http://dx.doi.org/10.1080/03043790500213136

Huang, S.J., Yang, L., \& Zhang, Z.R. (2004). Constructing Practice Bases for Engineering Specialties and Study on New Practice Modes. Journal of Guangdong University of Technology (Social Sciences Edition), (04), 52-55.

Jesiek, B., Zhu, Q., Woo, S., Thompson, J., \& Mazzurco, A. (2014). Global Engineering Competency in Context: Situations and Behaviors. Online Journal for Global Engineering Education, 8(1). Retrieved from http://digitalcommons.uri.edu/ojgee/vol8/iss1/1

Jia, Y. Q., Yan, X.G., \& Li, S.J. (2014). Research and Practice of Educating High-quality Engineering Talent through Industry-Academia-Research Cooperation. Way of Success, (02), 9-10.

Lin, D.Y., \& Pan, H.Z. (2013). Research on Practical Training Reform in Post-secondary Engineering Education. China Electric Power Education, (25), 162-163. 
Lin, J. (2013). Practice and Progress Analysis on "Zhuoyue Engineering Education Plan". Research on Higher Education in Engineering, 4.

Liu, Q.H. (2013). The Effect of Mechanical Practical Training on EQO (Essential Quality Oriented) Education. Technological Pioneers, (12), 162.

Liu, S.C. (2005). Emphasize Practical Training; Improve Efficiency. Vocational Education Research, (03), 109.

Liu, X. (2013). Case Studies about Sino-Foreign Joint Programs in Engineering Education (Master's thesis). East China University of Science and Technology, Shanghai, China.

Lohmann, J. R. R. J., Howard A. Hoey, J. Joseph. (2006). Defining, developing and assessing global competence in engineers. European Journal of Engineering Education, 31(1), 119-131. http://dx.doi.org/10.1080/03043790500429906

Mincer, J. (1958). Investment in Human Capital and Personal Income Distribution. Journal of Political Economy, 66(4), 281-302. http://dx.doi.org/10.1086/258055

Neapolitan, J. (1992). The Internship Experience and Clarification of Career Choice. Teaching Sociology, 20(3), 222-231. http://dx.doi.org/10.2307/1319064

Qiao, Y. (2005). Research on the Reform of Engineering Practice Pattern. Journal of North-Central University (Social Science), (02), 97-98.

Shao, C.Y. (2013). Post-secondary Engineering Practical Training and Innovation. Education Review, (06), $27-29$.

Tang, D., Xiao, Y., \& Guo, L. (2013). Construction Strategy of Off-Campus Practice Base of Engineering Major in Local Universities. Journal of Chengdu Textile College, (01), 40-42+48.

Taubman, P. (1976). The determinants of earnings: Genetics, family, and other environments: A study of white male twins. The American Economic Review, 858-870.

Tong, Y.J. (2013). Teaching and Learning Research on How to Develop Engineering Students' Comprehensive Skills by Practical Training. Heilongjiang Science, (12), 185.

U.S. Immigration and Customs Enforcement. (2015). Practical Training. Retrieved July 23, 2015, from http://www.ice.gov/sevis/practical-training

USTB (2006). CPT Funding Management Rules. Beijing: University of Science and Technology Beijing.

Wang, W.Z., Zhang, J.R., \& Yang, C.G. (2010). Exploration on Practical Training Base Construction for Engineering Education. Forum of Contemporary Education, (02), 32-33.

Wei, D.X., Ye, W.D., \& Zhang, J.L. (2008). Exploration on Engineering Practical Training in Agriculture Universities. China Modern Educational Equipment, (04), 127-128.

Wu, J. (2011). Exploration and Practice of the Practice Teaching Reform on Engineering Disciplines. Research and Exploration in Laboratory, (06), 166-168.

Xi, J.J., \& Wu. Z. (2002). Improve Engineering Practical Training, Develop Creative Engineering Talent. Liaoning Education Research, (07), 57-59.

Yan, Q.S., Ai, Y.L., Chen, L.P., \& Liu, G.M (2009). Construction and exploration of outside-school practice bases for aviation academy engineering specialties under the new situation. Laboratory Science, (04), 166-169.

Yuan, Q. (2014). Problems and Solutions to Practical Training in Engineering Education. Forum of Teaching and Learning, (13), 243-243,244.

Zhang, G. (2014). Engineering Professors Complain: as students lack of practical skills, practical training becomes headache. China Youth Daily. Beijing

Zhao, H.Y., Xu, B., Liu, B.X., \& Zhang, X.L. (2013). Discussion on Teaching Reform for Metalworking Practice based on the Target of Training Outstanding Engineers. Laboratory Science, (04), 155-158.

Zhou, W.M., \& Jiang, W.B. (2013). Exploration and Practice of Metalworking Practice Teaching Reform. Journal of Zhejiang University of Science and Technology, (06), 476-480.

Zhou, X.C. (2008). Exploration and Practice of Off-Campus Practice in Engineering Education. China Science and Technology Information, (14), 289-290.

Zou, G. Z. (2009). Engineering Profession Practice to Student Ability Formation of Meaning Investigation. Science \& Technology Information, (15), 115+101. 


\section{Notes}

Note 1. There is no exact equivalent of Chinese Sheng Chan Shi Xi in other post-secondary education systems. CPT is the closest that we can refer to. Since CPT is a legal term in the U.S, we provide the definition, reference, and explain the similarities of CPT and Sheng Chan Shi Xi.

Note 2. By definition, China's engineering higher-education covers 22 programs, which are Applied Geology, Materials Science, Mechanical Engineering, Instrument \& Meter, Thermal \& Nuclear Energy, Electronics \& Information, Civil Engineering \& Architecture, Hydraulics, Survey \& Measure, Environment \& Safety, Chemical Engineering \& Pharmaceutics, Transportation, Oceanic, Light Industry, Textile \& Food, Aeronautics \& Astronautics, Weaponry, Engineering Mechanics, Biotechnology, Agriculture Engineering, Forestry Engineering, and Public Safety Technology. This list is from China Ministry of Education's statistical instruments. http://www.moe.edu.cn/publicfiles/business/htmlfiles/moe/moe_1653/200710/26613.html

Note 3. Reference: a CPT guide book for Computer Science students of a university in Shaanxi, China.

Note 4. Data source: Enrollment data were from Ministry of Education of the People's Republic of China. http://www.moe.edu.cn/publicfiles/business/htmlfiles/moe/s7567/201308/156602.html Engineer data were from National Bureau of Statistics of China. http://data.stats.gov.cn/index

Note 5. RMB refers to Ren Min Bi, China's official currency. 1RMB=0.16 US Dollar. According to USTB (2006), the direct cost of CPT per student per day includes housing (RMB12), food (RMB 2), and fees (RMB 2.5), so the total is RMB 16.5. We used CPI index to convert this price to 2012's real cost. $\mathrm{CPI}_{2006}=471.0$ and $\mathrm{CPI} 2012=579.7$, so CPT's cost in 2012=RMB 16.5*(579.7/471.0) $=$ RMB 20.2. CPI index is from National Bureau of Statistics of China. http://data.stats.gov.cn/search/keywordlist2?keyword=CPI

Note 6. This research cannot employ NPV because cost data are not available.

Note 7. CPT is the treatment in this research. As this study is not a real experiment, treatment group refers to students that received the intervention (CPT). The control (comparison) group is students without CPT experience. In the matched pair, the student in the control group is identical to his/her pair minus the CPT experience. It should be noted that not all colleges/universities requires CPT.

Note 8. Ignorability means $Y(0), Y(1) \perp Z \mid X$, referred to "ignorability of the assignment mechanism" (Rubin, 1978)

Note 9. Since one observation ( $\mathrm{ID}=400334$ ) has not yet joined the labor force (year_com=2015). He/she was removed from the sample for the purpose of this study.

Note 10. Although 21 observations selected 'others', no detailed information was included in the conducted survey, therefore we leave these observations out. It would be useful to get text information about 'other' and then reclassify.

Note 11. 5 refers to doctoral degree and 0 refers to primary school or under. One engineer's mother has a doctoral degree.

Note 12. Unit is RMB $10,000(\$ 1,628)$.

Note 13. This percentage is by row.

Note 14. As of year 2014, an individual's income is taxed progressively at 3-45\% in China.

Note 15. Red solid line is the treatment group (sample size: 1,580) and blue dashed line is the control (sample size: $629)$. Income levels range from RMB 30,000 to $570,000(\$ 4,886$ to 92,849$)$.

Note 16. Results reported in this paper are from nearest neighbor matching approach. We tried several other matching approaches: K-closet, radius-standard), and radius-kernel. Results are quite similar.

Note 17. We choose this income level because this is where the mean locates. We've tried other levels of earnings. RMB 50,000-70,000 the only income level that the coefficient of CPT is significant. 